\title{
Hepatitis E virus antibodies in HIV-infected patients and blood donors from western Poland: A preliminary report
}

\author{
Maciej Bura ${ }^{1, A-F}$, Alicja Bukowska ${ }^{2, A, B}$, Aleksandra Bura ${ }^{3}$, B, E, Michał Michalak ${ }^{4, C}$, Iwona Mozer-Lisewska ${ }^{1, A, E, F}$ \\ ${ }^{1}$ Department of Infectious Diseases, Hepatology and Acquired Immunodeficiences, Poznan University of Medical Sciences, Poland \\ ${ }^{2}$ Regional Blood Center, Poznań, Poland \\ ${ }^{3}$ Department of Infectious Diseases, Joseph Strus Multidisciplinary City Hospital, Poznań, Poland \\ ${ }^{4}$ Department of Computer Science and Statistics, Poznan University of Medical Sciences, Poland \\ A - research concept and design; B - collection and/or assembly of data; C - data analysis and interpretation; \\ $D$ - writing the article; $E$ - critical revision of the article; $F$ - final approval of article
}

\section{Address for correspondence}

Maciej Bura

E-mail:mbura@umed.poznan.pl

\section{Funding sources}

The study was funded by Poznan University of Medical Sciences (no. 502-01-02205314-04519) and the Regional Blood Center in Poznań.

\section{Conflict of interest}

None declared

\section{Acknowledgements}

The authors would like to thank dr Hanna Skalisz (Regional Blood (enter in Poznań) for her kind support in the organization of this study and dr Michał Chojnicki (Department of Infectious Diseases, Joseph Strus Multidisciplinary City Hospital in Poznań) for his substantial aid in the transportation of samples.

Received on November 30, 2015

Revised on January 15, 2016

Accepted on March 23, 2016

\begin{abstract}
Background. Hepatitis E virus (HEV) infection is an emerging problem in industrialized countries, including Europe. Little data exists on HEV seroprevalence in Poland.

Objectives. The aim of this study was to assess the prevalence of anti-HEV lgG antibodies in Polish patients infected with the human immunodeficiency virus (HIV) and blood donors.

Material and methods. Two hundred and ten individuals ( $n=105$ of HIV-infected patients and $n=105$ of age- and sex-matched blood donors from the same area; 178 men and 32 women), aged 18-50 (median age: 38 years), were tested for the presence of anti-HEV IgG antibodies with the EUROIMMUN Anti-Hepatitis E Virus (HEV) ELISA (lgG) tests (Lübeck, Germany). Additionally, some simple clinical and laboratory data was collected.

Results. The overall anti-HEV IgG prevalence was 2.4\% (5/210). One HIV-positive patient (0.95\%) and 4 blood donors (3.8\%) were seropositive $(p=0.1745)$. All the HEV-exposed individuals were men with a history of travel abroad and no icteric disease in the past.

Conclusions. Exposure to HEV infection among Polish HIV patients and blood donors seems to be uncommon. Data on this issue is scarce and conflicting for HIV-infected individuals. Further investigations applying different serological tests and concomitant HEV RNA testing are needed to reliably assess the risk and practical impact of HEV infection in Poland.
\end{abstract}

Key words: HIV, seroprevalence, blood donors, HEV

DOI

$10.17219 /$ acem $/ 62353$

Copyright

Copyright by Author(s)

This is an article distributed under the terms of the

Creative Commons Attribution Non-Commercial License

(http://creativecommons.org/licenses/by-nc-nd/4.0/) 
The hepatitis E virus (HEV) is a small virus classified within the Hepeviridae family. HEV infection is considered as an emerging problem in developed parts of the world. ${ }^{1}$ Many cases of locally acquired acute hepatitis E have been recognized in Europe. ${ }^{2}$ Moreover, in some specific populations of immunocompromised individuals (including HIV-infected patients), HEV infection can cause chronic hepatitis with the potential for progression toward liver cirrhosis. ${ }^{3,4}$ Data on the exposure of Polish HIV patients to HEV infection is limited to 1 uncontrolled study. ${ }^{5}$ To the best of our knowledge, there are no Polish reports discussing this issue in relation to blood donors (BDs).

\section{Objective}

The aim of this study was to investigate the prevalence of anti-HEV IgG antibodies (anti-HEV) in Polish HIV patients and in a comparable group of healthy BDs.

\section{Material and methods}

During a 5-month period (from March 2015 to July 2015), we tested 210 individuals, that is, 105 HIV-infected Polish patients of Joseph Strus Multidisciplinary City Hospital in Poznań, western Poland, and 105 age- and sex-matched healthy BDs from the same area for the presence of antiHEV IgG (anti-HEV) antibodies using a commercial ELISA kit (Anti-Hepatitis E Virus (HEV) ELISA [IgG]; EUROIMMUN Medizinische Labordiagnostika AG, Lübeck, Germany), in accordance with the manufacturer's instructions (we performed the quantitative version of the testing with results equal to or higher than $2.2 \mathrm{IU} / \mathrm{mL}$ being interpreted as positive). This test is based on recombinant target antigens of HEV genotypes 1 and 3 expressed in E. coli.

Screening for HIV, HBV and HCV infection was done with chemiluminescent microparticle immunoassays (ARCHITECT system, Abbott Laboratories; Wiesbaden, Germany or Sligo, Ireland). For HIV-RNA, HBV-DNA and HCV-RNA assessment in blood donors, Cobas TaqScreen MPX v. 2.0 kits (Roche Diagnostics GmbH, Mannheim, Germany) were used. All BDs were negative in the screening and nucleic acid testing.

This work was approved by the Bioethics Committee of Poznan University of Medical Sciences (reference number 157/15). All patients and blood donors signed an informed consent.

The test for proportions was performed with STATISTICA v. 12 (StatSoft, Inc., Tulsa, USA) software; it was considered significant at $\mathrm{p}<0.05$.

\section{Results}

Both study groups consisted of 89 men (84.8\%) and 16 women (15.2\%), aged $18-55$ (mean $37.7 \pm 7.7$ years).
Among HIV-positive patients, 57 (54.3\%) were men having sex with men (MSM), 21 (20\%) were heterosexuals with no history of injection drug use, 18 individuals (17.1\%) declared parenteral use of psychoactive substances and 9 men $(8.6 \%)$ were bisexual. Seventy-one patients were under antiretroviral therapy (67.6\%). Their mean CD4 count was $504 \pm 300$ cells $/ \mathrm{mm}^{3}$ (range 14-1212; median 459). In 16 patients (15.2\%), the CD4 value was $<200$ cells $/ \mathrm{mm}^{3}$. Four HIV individuals were HBsAg-positive (3.8\%), 24 of the tested were anti-HCV-positive (22.9\%) and only one out of 105 patients was found to be both HBsAg and anti$\mathrm{HCV}$-positive. The alanine aminotransferase (ALT) level ranged from 8 to $306 \mathrm{IU} / \mathrm{L}$ (median $30 \mathrm{IU} / \mathrm{L}$ ), and in 73 of the HIV-infected persons (69.5\%), ALT values were normal on the day of the assessment of anti-HEV.

The overall HEV IgG seroprevalence was $2.4 \%(5 / 210)$. Only 1 out of the $105 \mathrm{HIV}+$ patients (0.95\%) was antiHEV-positive. He was a 30-year-old MSM, in whom HIV infection was diagnosed 10 months before his inclusion in this study and no treatment was started until the date of the CD4 count assessment concomitant with anti$\mathrm{HEV}$ testing. His CD4 value was 236 cells $/ \mathrm{mm}^{3}$. No increased aminotransferases activity or bilirubin level were observed in this patient. He reported no icteric disease in the past. Of note, the patient revealed he had traveled abroad, also to highly-endemic HEV infection areas in developing countries.

Among BDs, 4 out of 105 persons (3.8\%) were anti$\mathrm{HEV}$ positive. All seropositive individuals were men aged 34-55 (mean 42 years) with a history of multiple blood donation and no significant medical record. All of them had visited some European countries only. There was no significant difference in $\mathrm{HEV}$ seroprevalence between the HIV-positive patients and BDs ( $p=0.1745$; the test for proportions).

\section{Discussion}

In different investigations from western Europe for HIVpositive individuals, the HEV seroprevalencevaried from $1 \%$ in Scotland and Croatia to $10 \%$ in Spain. ${ }^{6-9}$ In our neighbor countries, Pischke et al. found anti-HEV positivity of $4.9 \%$, whereas Balayan et al. reported the value of $11.1 \%$ in German and Russian HIV-infected patients, respectively. ${ }^{10,11}$ In BDs, the HEV seroprevalence assessed with the use of highly-sensitive tests varied from $4.7 \%$ in Scotland to $52.5 \%$ in the hyper-endemic area of south-western France. ${ }^{12,13}$ In Germany, this value was $5.9-6.8 \% .^{14,15}$

Only a few studies have compared the frequency of anti-HEV positivity in HIV-infected individuals with controls, suggesting similar or higher HEV seroprevalence in HIV-positive patients. ${ }^{16-18}$

The results of the current analysis are strikingly different from conclusions suggested by our previous study about anti-HEV prevalence in Polish patients, including 
HIV-positives; in the latter group, these antibodies were detected in $21.3 \%$ out of 61 cases. ${ }^{5}$

It is known that the performances of various assays used for HEV seroprevalence assessment can differ significantly, but some recent data suggests that EUROIMMUN kits have similar sensitivity to tests of other manufacturers'. ${ }^{13,19-22}$ However, the comparative specificity of anti-HEV kits has not been extensively investigated and, in our opinion, it could be a possible source of the significant discrepancy in the only 2 available HEV seroprevalence estimates in Polish HIV patients. This issue has not been ultimately resolved and requires further study.

The current study has several limitations: first, the number of the tested participants was relatively low; second, the upper value of the age range ( 55 years; due to the age profile of BDs) could, at least partially, influence the HEV seroprevalence data in terms of the lower frequency of anti-HEV in younger individuals reported by many other authors; ${ }^{9,21,23}$ third, no HEV-RNA detection was performed in this study. Although HEV-RNA positivity is infrequent in asymptomatic inhabitants of Western countries, it is the direct indicator of potential risks related to HEV infection (chronic hepatitis E in HIV patients and transfusion-related risk for immunocompromised recipients of blood products).

\section{Conclusions}

The results of the current study suggest that exposure to HEV infection among Polish HIV patients and BDs is uncommon. In view of the fact that available data on this issue is scarce and conflicting for HIV-infected individuals, further investigations with the use of different serological tests and concomitant HEV-RNA testing are needed to reliably assess the risk and the practical impact of HEV exposure in Poland.

\section{References}

1. Bendall R, Legrand-Abravanel F, Xia NS, ljaz S, Izopet J, Dalton HR. Hepatitis E. Lancet. 2012;379:2477-2488.

2. Lapa D, Capobianchi MR, Garbuglia AR. Epidemiology of hepatitis E virus in European countries. Int J Mol Sci. 2015;16:25711-25743.

3. Jardi R, Crespo M, Homs M, et al. HIV, HEV and cirrhosis: Evidence of a possible link from eastern Spain. HIV Med. 2012;13:379-383.

4. Neukam K, Barreiro P, Macías J, et al. Chronic hepatitis E in HIV patients: Rapid progression to cirrhosis and response to oral ribavirin. Clin Infect Dis. 2013;57:465-468.

5. Bura M, Michalak M, Chojnicki M, Czajka A, Kowala-Piaskowska A, Mozer-Lisewska I. Seroprevalence of anti-HEV IgG in 182 Polish patients. Postepy Hig Med Dosw. 2015;69:320-326.

6. Bradley-Stewart AJ, Jesudason N, Michie K, Winter AJ, Gunson RN. Hepatitis E in Scotland: Assessment of HEV infection in two high-risk patient groups with elevated liver enzymes. J Clin Virol. 2015;63:36-37.

7. Daković Rode O, Jemeršić L, Brnić $D$, et al. Hepatitis $E$ in patients with hepatic disorders and HIV-infected patients in Croatia: Is one diagnostic method enough for hepatitis E diagnosis? Eur J Clin Microbiol Infect Dis. 2014;33:2231-2236.

8. Mateos-Lindemann ML, Diez-Aguilar M, Galdamez AL, Galán JC, Moreno A, Pérez-Gracia MT. Patients infected with HIV are at high-risk for hepatitis E virus infection in Spain. J Med Virol. 2014; 86:71-74.

9. Rivero-Juarez A, Martinez-Dueńas L, Martinez-Peinado A, et al. High hepatitis $E$ virus seroprevalence with absence of chronic infection in HIV-infected patients. J Infect. 2015;70:624-630.

10. Pischke $\mathrm{S}, \mathrm{Ho} H$, Urbanek $\mathrm{F}$, et al. Hepatitis $\mathrm{E}$ in HIV-positive patients in a low-endemic country. J Viral Hepat. 2010;17:598-599.

11. Balayan MS, Fedorova OE, Mikhailov MI, et al. Antibody to hepatitis E virus in HIV-infected individuals and AIDS patients. J Viral Hepat. 1997;4:279-283.

12. Cleland A, Smith L, Crossan C, et al. Hepatitis E virus in Scottish blood donors. Vox Sang. 2013;105:283-289.

13. Mansuy JM, Bendall R, Legrand-Abravanel F, et al. Hepatitis E virus antibodies in blood donors, France. Emerg Infect Dis. 2011;17: 2309-2312.

14. Vollmer T, Diekmann J, Johne R, Eberhardt M, Knabbe C, Dreier J. Novel approach for detection of hepatitis $E$ virus infection in German blood donors. J Clin Microbiol. 2012;50:2708-2713.

15. Juhl D, Baylis SA, Blümel J, Görg S, Hennig H. Seroprevalence and incidence of hepatitis $E$ virus infection in German blood donors. Transfusion. 2014;54:49-56.

16. Keane F, Gompels M, Bendall R, et al. Hepatitis E virus coinfection in patients with HIV infection. HIV Med. 2012;13:83-88.

17. Riveiro-Barciela M, Buti M, Homs M, et al. Cirrhosis, liver transplantation and HIV infection are risk factors associated with hepatitis $E$ virus infection. PLoS One. 2014;9:e103028.

18. Scotto G, Grisorio B, Filippini P, et al. Hepatitis E virus co-infection in HIV-infected patients in Foggia and Naples in southern Italy. Infect Dis. 2015;47:711-717.

19. Bendall R, Ellis V, ljaz S, Ali R, Dalton H. A comparison of two commercially available anti-HEV IgG kits and a re-evaluation of antiHEV IgG seroprevalence data in developed countries. J Med Virol. 2010;82:799-805.

20. Wenzel JJ, Preiss J, Schemmerer M, Huber G, Jilg W. Test performance characteristics of Anti-HEV IgG assays strongly influence hepatitis E seroprevalence estimates. J Infect Dis. 2013;207:497-500.

21. Dreier J, Juhl D. Autochthonous hepatitis E virus infections: A new transfusion-associated risk? Transfus Med Hemother. 2014;41:29-39.

22. Avellon A, Morago L, Garcia-Galera Del Carmen M, Munoz M, Echevarría JM. Comparative sensitivity of commercial tests for hepatitis E genotype 3 virus antibody detection. J Med Virol. 2015;87: 1934-1939.

23. Politou M, Boti S, Androutsakos T, Valsami S, Pittaras T, Kapsimali V. Seroprevalence of hepatitis E in HIV infected patients in Greece. J Med Virol. 2015;87:1517-1520. 